\title{
FACILITANDO A VIDA DO FACILITADOR: A POLIDOCÊNCIA NA ELABORAÇÃO DE CURSOS ONLINE
}

\author{
SÃO CARLOS/SP MAIO/2018 \\ $\begin{array}{cc}\text { Helena Gordon Silva Leme } & \text { - EDUCONECTA - hgsleme@gmail.com } \\ \text { Kenia Rosa de Paula Nazário } & \text { - EDUCONECTA - keniarosa.ead@gmail.com } \\ \text { Rosimeire Moreira Vizentim } & \text { - EDUCONECTA - vizentim@gmail.com }\end{array}$
}

Tipo: Relato de Experiência Inovadora (EI)

Categoria: Métodos e Tecnologias

Setor Educacional: EDUCAÇÃO CONTINUADA EM GERAL

\begin{abstract}
RESUMO
Este artigo tem por objetivo apresentar um relato de experiência, destacando a polidocência no planejamento de cursos online voltados para formação continuada de professores e profissionais da área da educação. O cenário é o da equipe docente e não docente que atua no Ambiente Virtual de Aprendizagem - AVA da EduConecta, utilizando a plataforma Moodle como suporte aos professores interessados em ofertar cursos diversos na modalidade a distância. O contexto de trabalho parte do princípio da importância de cada ator da equipe polidocente na organização de cursos para professores e demais profissionais que buscam o suporte do uso da tecnologia no âmbito educacional. A metodologia utilizada para o desenvolvimento do estudo é de caráter qualitativo, percorrendo o modelo ADDIE e baseado na experiência dos diversos atores da equipe da EduConectanas etapas de elaboração, planejamento e concepção de cursos. Como facilitadores desse processo, a equipe da EduConecta busca dar suporte ao desenvolvimento das competências tecnológicas a partir do uso dos ambientes virtuais de aprendizagem e das metodologias utilizadas para potencializar o processo de ensino e aprendizagem.
\end{abstract}

Palavras-chave: Polidocência.Facilitadores.Modelo ADDIE.Tecnologia educacional. 


\section{1 - Introdução}

A educação a distância é caracterizada como modalidade educacional na qual a mediação didático-pedagógica, nos processos de ensino e aprendizagem, ocorre com a utilização de meios e tecnologias de informação e comunicação. De acordo com Gomez (2010, p.09): "Estamos caminhando para uma fase de convergência e integração das mídias. (...) Todos podem ser produtores e consumidores de informação". Mill, Ribeiro e Oliveira (2010) afirmam que, na educação presencial, predomina a responsabilização de um único professor pelas diversas atividades integrantes de sua disciplina. Ao contrário, no âmbito da EaD, a responsabilidade pelas atividades é distribuída. Segundo os autores, "[...] não existe a opção de um único profissional realizar toda a 'aula' porque, via de regra, a quantidade de alunos ou a complexidade do processo de trabalho na EaD impossibilita a unidocência".

Portanto, na EaD:

há um "trabalhador coletivo" exercendo as atividades do trabalhador-professor na educação presencial: passamos da unidocência para a polidocência. $\mathrm{Na}$ EaD, normalmente cabem diferentes profissionais as tarefas de produzir o conteúdo do curso, de organizar didaticamente o material, converter o material para linguagem da mídia (impressa, audiovisual, virtual, etc.) de coordenar todas as atividades, gerenciar de um curso e manejar/gerenciar a turma, entre outras (Mill, Ribeiro e Oliveira 2010, p.25).

Pode não ser impossível, mas as dificuldades que o professor pode enfrentar para dar conta de todo o processo de organização de um curso na EaD serão relativas ao seu grau de disponibilidade de tempo e conhecimento e uso das tecnologias, além das tarefas pedagógicas propriamente ditas. Embora existam muitos cursos e treinamentos voltados ao docente para que ele aprenda a lidar com os avanços tecnológicos disponíveis para a elaboração de cursos, é importante que esse professor receba e troque informações com outros participantes da equipe polidocente para que seu trabalho seja mais eficiente, tanto no uso de diferentes mídias, como na atuação pedagógica e facilitadora da aprendizagem no ambiente virtual.

Nesse contexto a atuação da equipe EduConecta apoia-se na experiência de seus colaboradores na composição de equipes polidocentes que ofertam cursos online e do conhecimento das diversas áreas que abrangem a EaD. Oferece aos professores interessados em ministrar cursos, suporte em todas as etapas para facilitar a sua atuação como facilitador da aprendizagem de seus alunos. Assim, possibilita que o professor, dentro da equipe polidocente, passe a ter um papel específico, "não mais como provedor e controlador direto das informações e da aprendizagem, mas como planejador e gestor das estratégias adequadas, além de mediados de todos os recursos disponíveis. " (PETEROSSI e ITOCAZU, 2005, p. 106) 
A equipe EduConeta tem como objetivo relacionar Educação e Tecnologia através de pesquisas e desenvolvimento de soluções que unam estes conceitos, permitindo novas práticas pedagógicas para o cotidiano escolar. $O$ foco está na utilização de tecnologias em sala de aula e em ambientes virtuais de aprendizagem, com comprometimento com a Sociedade, sobretudo com a Educação. Sob o modo de organização polidocente, o saber que seria detido por um único educador no ensino presencial é segmentado e distribuído a vários profissionais. Assim, na $\mathrm{EaD}$, equivalendo à figura do professor da educação presencial, surgem categorias profissionais redefinidas: como o docenteconteudista, o docente-tutor (virtual e presencial), o docente projetista educacional (ou designer instrucional ou estrategista pedagógico), entre outras (Mill, Ribeiro e Oliveira, 2010, p. 27-28). Os autores destacam que "a esse conjunto articulado de trabalhadores, necessários para a realização das atividades de ensino-aprendizagem na EaD, denominamos de polidocência".

Nessa equipe polidocente o professor conteudista é o responsável pela preparação dos materiais didáticos de uma disciplina ou curso. O professor responsável é aquele que acompanha a turma durante a execução da disciplina ou curso. Ele também acompanha e orienta a sua equipe de tutores. Alguns cursos não possuem esse sujeito, passando diretamente para os tutores a responsabilidade pelo acompanhamento da aplicação do conteúdo aos alunos.

Outro sujeito que compõe a equipe polidocente proposta pelos autores é o docente tutor. O trabalho de tutoria em geral é desenvolvido pelo tutor virtual e o tutor presencial. O tutor virtual tem seu foco dirigido ao conteúdo a ser trabalhado com os alunos e normalmente tem formação especializada na área em que atua. Segundo Mill, Ribeiro e Oliveira (2010, p. 35), "a função de tutor virtual é demasiadamente complexa e trabalhosa para atender um grupo com mais de 25 alunos num determinado conteúdo". O tutor virtual faz o atendimento de forma online, seja pelo Ambiente Virtual de Aprendizagem (AVA), seja por emails, chats ou bate-papos. Por sua vez, o tutor presencial tem a função de atender os alunos nos polos, sanando dúvidas pontuais, auxiliando a equipe nas atividades presenciais, avaliativas ou não, e mediando o processo junto aos alunos. Nem todos os cursos incluem a figura do tutor presencial na equipe polidocente.

A equipe também é composta pelo Designer Instrucional. Uma das metáforas usadas para definir o papel do designer instrucional é o de tradutor. Nesse papel, o DI atua na tradução do conteúdo desenvolvido pelo conteudista, muitas vezes o próprio professor responsável pelo curso ou um especialista designado para essa tarefa, para o ambiente virtual no qual os processos de interação voltados ao ensino e aprendizagem ocorrerão. 
Desta maneira, sua tarefa é traduzir o conteúdo teórico através de recursos e ferramentas interativas no AVA para que de forma síncrona e assíncrona auxiliem na promoção da aprendizagem.

A equipe polidocente não necessariamente é composta por esses sujeitos mencionados em todas as modalidades de EaD. Além desses sujeitos, a equipe multidisciplinar pode ter outros profissionais não docentes que são responsáveis pela mídia impressa, audiovisual e virtual, e do suporte técnico, além de outros eventuais. Entende-se que todos os profissionais que atuam no processo de ensino-aprendizagem constituem a equipe polidocente.

Em geral, o docente autor (ou conteudista) é quem organiza o conteúdo que será oferecido no curso. Esse conteúdo é organizado contemplando o material didático e os recursos tecnológicos que vão possibilitar a interação e colaboração para dar suporte aos processos de ensino e aprendizagem. De acordo com Cortelazzo(2013, p. 156), "o material didático é aquele preparado para dar continuidade à prática pedagógica iniciada pelo professor e pelo tutor com o aluno". Ainda segundo o autor (p. 160), "o material didático também é um apoio para a mediação da tutoria na orientação do aluno e no estudo em equipe para realização das atividades de aprendizagem básicas para avaliação processual".

\section{2 - O Modelo ADDIE e a atuação da equipe polidocente}

A metodologia utilizada pela equipe na Educonecta no Design de cursos é o Modelo ADDIE (Analysis, Design, Development, Implementation, Evaluation - em Português: Análise, Projeto, Desenvolvimento, Implementação, Avaliação). Cada etapa necessita do trabalho colaborativo da equipe polidocente. Os diversos participantes serão relacionados a cada etapa, como descritas a seguir:

Análise - A etapa de análise consiste na compreensão do problema educacional bem como na projeção de sua solução aproximada. Apresentam-se os levantamentos das necessidades educacionais, a caracterização do público-alvo, objetivos e restrições, Filatro (2008). Para a etapa de análise, a equipe Educonecta envia um formulário previamente elaborado ao professor responsável pela proposição do curso. Esse formulário permite fazer um levantamento das necessidades, análise do contexto, estudo preliminar do conteúdo do curso para a projeção dos resultados esperados. Elementos essenciais a essa etapa são: o diagnóstico das necessidades; a análise do público-alvo; a planilha de cronograma; a planilha de custo estimado; a definição dos recursos humanos, materiais, tecnológicos e financeiros. 
Assim, o professor responsável pelo curso integrando-se à equipe polidocente apresenta as informações necessárias e inicia o seu trabalho junto com o Designer Instrucional preparando o projeto do curso.

Projeto - O planejamento ou projeto do curso é o design da situação didática propriamente dita. As informações são expressas por meio das Unidades de Aprendizagem, Plano de atividades e informações adicionais solicitadas também via formulários online. Conforme Filatro (2008), Unidade de Aprendizagem (UA) é uma unidade atômica ou elementar que contém os elementos necessários ao processo de ensino-aprendizagem e sua granularidade é definida pelos seguintes aspectos: uma Unidade de Aprendizagem não pode ser subdividida em partes sem perder o significado; tem extensão e tempo limitados; e é autocontida no que se refere a processos, objetivos e conteúdos.

O Projeto em si é um esboço, que deve considerar todo planejamento e informações do curso. Esse esboço deve contemplar os objetivos de aprendizagem, o contexto e as características dos aprendizes, definição da estrutura do curso, detalhamento de atividades e conteúdos, carga horária de cada Unidade de aprendizagem, tema e subtemas que serão trabalhados, objetivos específicos. Os recursos, ferramentas e a abordagem pedagógica são discutidos com o Designer Instrucional que dará sugestões e contribuições ao professor proponente e em acordo com este fará o planejamento das atividades e recursos necessários ao curso. Para tanto, a equipe polidocente, professor responsável pelo curso, designer instrucional e algumas vezes, o professor conteudista trabalham colaborativamente na construção do Plano de atividades, conforme figura 1 , abaixo:

Figura 1 - Plano de Atividades

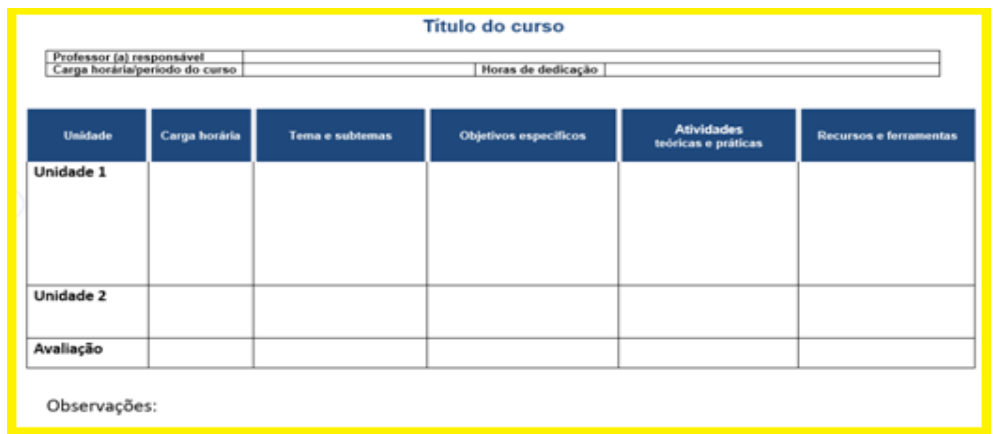

Fonte: http://educonecta.com.br

A estrutura do Plano de atividades consiste em informações gerais: Título do curso, 
nome do Professor responsável, carga horária do curso e horas de dedicação por semana. As informações mais específicas são divididas em:

- Unidade de aprendizagem: deve-se definir o nome do tema da unidade que está relacionado ao assunto principal a ser abordado naquela unidade.

- Temas e Subtemas: deve-se desmembrar o tema em subtemas.

- Objetivos Específicos: deve-se propor os objetivos estabelecidos para cada unidade de aprendizagem definindo os propósitos educacionais.

- Atividades Teórica e Práticas: deve-se definir as atividades teóricas e práticas que serão implementadas no ambiente virtual de aprendizagem. Neste campo também são definidos os tipos de avaliação de cada atividade que podem ser diagnósticas, formativas ou somativas. Também são disponibilizados a nota (se avaliativo) e o período (duração) em que as atividades ficarão disponíveis para o aluno.

- Recursos e ferramentas: Deve-se descrever os recursos e ferramentas disponíveis no ambiente virtual que contemplem a proposta de cada atividade, alguns exemplos de recursos: arquivos, livros, páginas, URLs, entre outros. As mídias que devem ser utilizadas, são textos, planilhas, apresentações, vídeos, hiperlinks, entre outros. Alguns exemplos de ferramentas disponíveis: Tarefa, Questionário, Fórum, Base de dados, Lição, Wiki, entre outras. (Esse campo é preenchido pelo $\mathrm{DI})$.

O Plano de Atividades é um guia para que toda equipe envolvida possa desenvolver as atividades planejadas no curso. Após a elaboração do plano de atividades, a equipe polidocente trabalha no desenvolvimento do curso.

Desenvolvimento - Considera-se esta etapa, como sendo a produção e a adaptação dos recursos e materiais didáticos impressos e/ou digitais, a parametrização de ambiente virtuais e a preparação dos suportes pedagógico, tecnológico e administrativo (FILATRO, 2008). Sendo uma etapa de cunho prático e executivo, seus resultados serão explicitados na etapa de Implementação do curso. Destacamos nessa etapa que existe uma equipe de profissionais que apoiam os professores na elaboração dos materiais didáticos, essa equipe denomina-se equipe multidisciplinar, é composta por mídia impressa (diagramadores, revisores, digitadores, desenhistas, gráficos, etc) e virtual (web designer, programador, diagramador, desenhista, técnico de informática, editores, etc - que organizam o material didático no ambiente virtual de aprendizagem) e outros eventuais profissionais (Mill, Ribeiro e Oliveira, 2010). O design do curso, em geral, fica a cargo do Designer Instrucional que não se preocupa apenas com a estética visual de um curso online, mas principalmente com sua concepção e estrutura pedagógica que 
foram definidos juntamente com o professor responsável pelo curso. Além disso, o DI comanda as seguintes ações para desenvolver o curso no AVA:

- produção do curso obedecendo-se as diretrizes do planejamento.

- conteúdos adaptados aos diversos suportes midiáticos pré-estabelecidos;

- configuração do AVA protótipo do curso.

Ainda na etapa de desenvolvimento, são preocupações para a equipe polidocente definir: Quais os prazos em que os alunos devem fazer as atividades? Que materiais que serão disponibilizados para os cursistas? Seleção das mídias e abordagem pedagógica.

Implementação- Naetapa de implementação do curso a equipe polidocente tem um trabalho colaborativo que envolve a equipe não docente de modo mais ativo num primeiro momento e, em seguida, a equipe docente atuando na execução e gerenciamento do curso. De acordo com Filatro (2008), "a implementação constitui a situação didática propriamente dita, quando ocorre a aplicação da proposta de design instrucional e subdivide-se aqui em duas fases: publicação e execução". Após o planejamento e implementação no AVA, na etapa de publicação a equipe trabalhará colocando o curso no ar. Assim, o curso estará pronto para ser executado e acessado por todos os participantes, como se pode observar na figura 2, abaixo:

Figura 2 -Curso publicado no AVA com ferramentas, orientações e recursos disponibilizados.

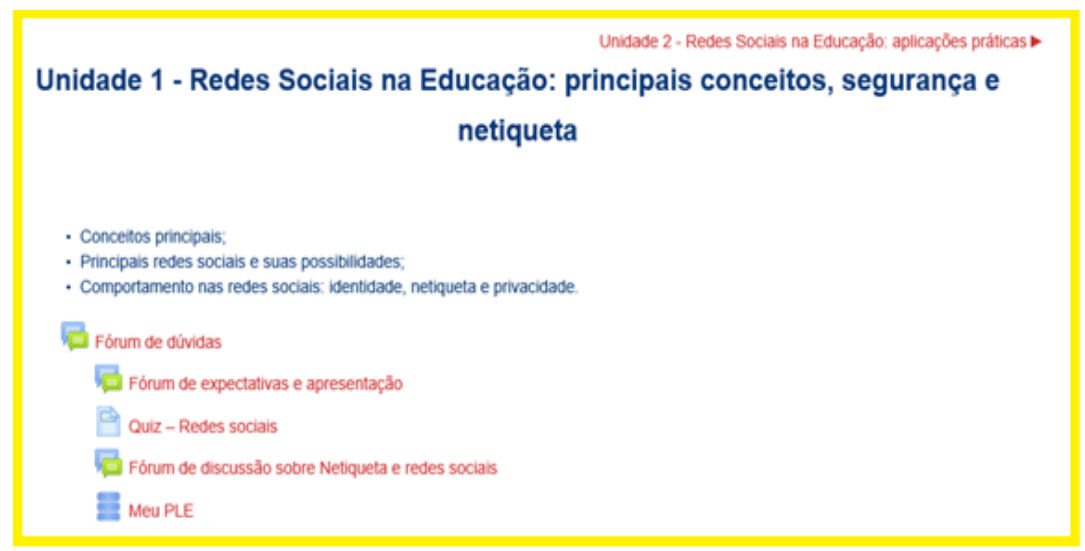

Fonte: http://educonecta.com.br

A etapa de execução vai mais uma vez envolver a equipe polidocente agora atuando na gestão e acompanhamento do curso através do professor responsável e tutores que 
darão suporte ao processo de aprendizagem dos alunos no AVA.

Avaliação - Esta etapa consiste nas considerações sobre a efetividade da solução proposta bem como a revisão das estratégias implementadas (FILATRO, 2008).

Quando falamos em avaliação, além daquela que ocorre dentro do curso pelos alunos, também estamos nos referindo à avaliação de todo o processo descrito até aqui. Ou seja, a avaliação do curso em si. Essa etapa de avaliação deve ocorrer em dois momentos: antes do curso ser colocado no ar e após a oferta do curso.

Os testes iniciais podem ser feitos por usuários que devem representar o público-alvo do curso, para passar uma experiência válida e a validação por parte do professor. Ao final dos testes, a equipe polidocente deve ser capaz de levantar dados que mostrem se o resultado foi eficiente, identificar pontos passíveis de correção e outros. Para a etapa de avaliação final, ao término do curso, a EduConecta utiliza a ferramenta de questionário online (Google Formulários) para verificar a autoavaliação (a participação dos alunos no curso segundo os mesmos) e a avaliação do curso na visão de cada aluno e do conjunto de alunos. Essa ferramenta permite a análise dos dados individuais e coletivos possibilitando verificar os pontos altos e as fraquezas do curso que irão permitir correções para próximas ofertas do curso. Em resumo, o modelo ADDIE fundamenta a atuação da equipe polidocente, e a atuação conjunta de seus elementos pode ser apresentada em suas diversas etapas.

Essa metodologia já foi aplicada em diversos cursos já finalizados, e outros cursos em produção. Segundo os textos de Leme e Nazario (2012, 2013 e 2014), observamos nos artigos já publicados, que descrevem estes cursos finalizados, que parte significativa dos docentes trabalham em conjunto com a equipe polidocente, o que facilita 0 desenvolvimento de todo processo de planejamento e implementação dos cursos, uma vez que a docência nessa modalidade requer conhecimentos e habilidades distintos da docência no ensino presencial. Desta maneira, o trabalho da equipe polidocente que envolve diversos profissionais com formações acadêmicas diferenciadas usa habilidades e conhecimentos específicos de suas áreas de atuação, trabalhando juntos, garantindo assim, a coerência entre todos os processos que resultarão em cursos que levem a uma aprendizagem significativa.

\section{Considerações finais}

Destacamos que a participação de todos os envolvidos na equipe polidocente que trabalham de forma articulada no planejamento do curso viabilizando o papel 
pedagógico por meio da tecnologia, ou seja, o professor trabalha junto a uma equipe buscando juntos atender os objetivos gerais do curso proposto.Assim sendo, não há protagonistas neste processo, mas sim, profissionais trabalhando em conjunto onde cada um dos envolvidos contribui com técnicas e habilidades para que o resultado final se converta em aprendizagem daqueles que farão o curso e questão, como destaca Mill (2010), que na EaD existe a "polidocência", a qual refere-se ao conjunto articulado de trabalhadores envolvidos no processo de ensino aprendizagem.

Entende-se que o planejamento realizado utilizando o modelo ADDIE fomenta 0 desenvolvimento das competências tecnológicas a partir do uso dos ambientes virtuais e as metodologias utilizadas para potencializar o processo de ensino e aprendizagem. Segundo Mill, Ribeiro e Oliveira (2010) a docência na EaD proporciona a muitos professores uma oportunidade de desenvolvimento profissional, visto que para exercerem a docência virtual precisam de outros saberes docentes, além dos que já vinham utilizando no ensino presencial.

Nesse sentido, o professor como facilitador do processo ensino aprendizagem faz parte da equipepolidocente (Prof, DI, tutor, equipe $\mathrm{TI}$ e audiovisual) que busca juntos a construção de conhecimentos que promovam uma aprendizagem significativa nos cursos online. A EduConecta tem como proposta a facilitação da aprendizagem respaldada pela tecnologia e construção pedagógica elaborada pela equipe polidocente facilitando a atuação do professor proponente de cursos.

\section{Referências}

BATISTA, Márcia; MENEZES, Marizilda. O design gráfico e o design instrucional na educação a distância. In Design, arte e tecnologia. n. 4. São Paulo: PUC-Rio e UnespBauru, 2008.

CORTELAZZO, Iolanda Bueno de Camargo. Prática pedagogica, aprendizagem e avaliação em educação a distância. - Curitiba: InterSaberes, 2013.

FILATRO, Andrea. Design instrucional contextualizado: educação e tecnologia, $2^{\underline{a}}$ edição: Editora SENAC. São Paulo, 2007.

FILATRO, Andrea. Design instrucional na prática. São Paulo: Pearson, 2008.

GOMEZ, M. V. Cibercultura, formação e atuação docente em rede: guia para professores. Brasília: Líberlivro, 2010. 
LEME, H.G.S.; NAZARIO, K.R.P. O uso de Redes Sociais e Tecnologia Móvel na EaD na perspectiva do Professor. In: $20^{\circ}$ Congresso Internacional de Educação a Distância, 2014, Curitiba-PR. EaD e a internacionalização da aprendizagem no Brasil, 2014.

MAIA, Carmem; MATTAR, João. ABC da EaD: a educação a distância hoje. São Paulo: Pearson Prentice Hall, 2007.

MELO e SILVA et al. Design Instrucional para uma Aprendizagem Significativa: pesquisa e extensão no caminho do desenvolvimento de tecnologias para a educação (2016). Disponível em: http://ceur-ws.org/Vol-1667/CtrlE_2016_AC_paper_57.pdf

MILL, Daniel; RIBEIRO; Luis; OLIVEIRA, Marcia (org.) Polidocência na educação a distância: múltiplos enfoques. São Carlos: EdUFSCar, 2010.

NAZARIO, K.R.P.; LEME, H.G.S. A Formação de Professores e o uso das Ferramentas Base de Dados e Fórum. In: ABED 19 Congresso Internacional de Educação a Distância: Bons Profissionais fazem bons programas de EaD: como estamos?, 2013, Salvador - BA. ABED 19ํㅡㄴ Congresso Internacional de Educação a Distância: Bons Profissionais fazem bons programas de EaD: como estamos?.

NAZARIO, K.R.P.; LEME, H.G.S. Aplicações Pedagógicas da ferramenta base de dados do Moodle na perspectiva da socialização do conhecimento. In: IX Congresso Brasileiro de Ensino Superior a Distância - ESUD, 2012, Recife-PE. IX Congresso Brasileiro de Ensino Superior a Distância, 2012.

PETEROSSI, H. G.; ITOCAZU, N. A. As novas tecnologias de informação e comunicação e a prática docente. In PETEROSSI, H. G.; MENEZES, J. G. C. (Org.). Revisando o saber e o fazer docente. São Paulo: Pioneira, p. 113-130, 2005.

SILVA, Edna; MENEZES, Estera. Metodologia da pesquisa e elaboração de dissertação. 4. ed. rev. atual. Florianópolis: UFSC, 2005. 